\title{
ANÁLISE ECONÔMICA DO SISTEMA DE SEGURANÇA DA PROPRIEDADE IMOBILIÁRIA: RELAÇÃO ENTRE O NÍVEL DE FACILIDADE NEGOCIAL E O CUSTO TRANSACIONAL
}

\author{
ECONOMIC ANALYSIS OF REAL ESTATE SECURITY SYSTEM: \\ RELATIONSHIP BETWEEN THE LEVEL OF BUSINESS AND EASE \\ THE TRANSACTIONAL COST
}

\author{
1Jose Eduardo De Moraes \\ ${ }^{2}$ Priscila Luciene Santos De Lima
}

\section{RESUMO}

O presente artigo tem como escopo elucidar a relação entre o grau de facilidade negocial e o custo transacional, apontando as serventias notariais e de registro como as instituições destinadas centrais nessa discussão. A análise dos indicadores dos relatórios Doing Business 2015 e 2016, do Banco Mundial, permite orientar a solução do problema. O grau de segurança jurídica proporcionada pelos registros públicos de tradição romano-germânica centraliza as discussões. Necessária a abordagem das origens da propriedade privada e do regime registral e notarial adotados no Brasil. O texto é traduz a Análise Econômica do sistema de proteção imobiliária vigente.

Palavras-chave: Serventias notariais e de registro, Segurança jurídica, Análise econômica, custo transacional, Custo brasil

\begin{abstract}
This work is scoped to elucidate the relationship between negotiation degree of ease and transactional costs, pointing to the notary and registration se for legal acts and businesses. The analysis of indicators such as Doing Business in 2015 and 2016 the World Bank, determines the purpose of the article. The legal certainty provided by the public records of RomanGermanic tradition compared to the system adopted by the Anglo-Saxon tradition of countries allows guide the solution of the question. The private property approach was necessary in its origins and the notarial and registration regime adopted in Brazil.
\end{abstract}

Keywords: Notary and registration service, Legal certainty, Economic analysis, Transactional cost, Cost brazil

\footnotetext{
${ }^{1}$ Mestrando em Direito Embresarial e Cidadania pelo Centro Universitário Curitiba - UNICURITIBA, Paraná, (Brasil) Email: tutortreinamento@gmail.com

${ }^{2}$ Mestranda em Direito Empresarial e Cidadania no Centro Universitário Curitiba - UNICURITIBA, Paraná, (Brasil).
} 


\section{INTRODUÇÃO}

Acostumamo-nos a conviver com a ideia de que o Brasil é a Republica Cartori, (CONSTANTINO, 2016), conotação conferida ao país do retrocesso burocrático, das rotinas exageradas, das estruturas arcaicas, dos custos inúteis e da ineficiência administrativa.

O sentimento pejorativo atribuído à expressão garante um sentimento de revolta contra as instituições ligadas ao Estado, especialmente aquelas que, coloquialmente, são recorrentemente atreladas ao Brasil atrasado.

Os serviços notariais e de registro são comumente relacionados a isso. Não é sem sentido que a expressão faça referência ao Estado cartorial. Essa visão do Estado racional- formalista repercute nas discussões sociais, nas conversas familiares, mas também transcende essas fronteiras.

Estudo divulgado pelo Students For Liberty Internacional Network indica que o Brasil ocupa a $103^{\circ}$ posição (entre 153 países avaliados) no Índice de Liberdade Econômica, que mede o grau de liberdade econômica de um país, relativamente às políticas e instituições.

No relatório Doing Business 2015 - Going Beyond Efficiency, publicado pelo Banco Mundial, o Brasil ocupa a $120^{\circ}$ posição (entre 189 países avaliados) no ranking que mede o grau de facilidade de fazer negócios. (ESTUDANTES, 2016).

Um dos fatores utilizados na metodologia de confecção desta publicação anual do Banco Mundial é a registering property, que considera o número de procedure, o time, e o cost (relativamente ao valor do imóvel transacionado). Neste quesito de avaliação, o Brasil ocupa posição ainda pior, estabelecendo-se na $138^{\circ}$ colocação.

O presente estudo tem o objetivo de analisar a correlação entre os índices que apontam o grau de dificuldade negocial e de liberdade econômica do Brasil e o chamado custo das transações imobiliárias, perquirindo os eventuais pontos de desacerto no sistema de transito imobiliário adotado.

Neste sentido, abordando de maneira doutrinária e empírica, com a utilização de indicadores internacionais, a finalidade do artigo é desvendar se as instituições notariais e registrais brasileiras merecem ser incluídas nas críticas ao sistema de transmissão imobiliária. 


\section{PROPRIEDADE PRIVADA}

A propriedade privada é um marco do Estado liberal, e consequência da argumentação do liberalismo. É o exercício das faculdades do homem livre, que seleciona fração dos bens escassos para si em detrimento de todos os outros.

A relação entre o solo e o homem sempre existiu. Iniciou com o homem nômade, que buscava novas áreas para explorá-la (através das atividades de extração e caça). Quando o limite do aproveitamento chegava ao fim, o homem decida procurar outros locais para viver. Nessa conduta, o homem espalhou-se pelos locais mais longínquos da Terra.

Só muito tempo depois, que remonta ao período neolítico, o homem passou, gradativamente, a fixar-se no solo. Porém, como é sabido, essa tendência humana de buscar desbravar novos locais resistiu em vários povos, havendo inclusive nos dias atuais quem a pratique.

Ao fim desse processo de exploração da Terra, o homem havia conhecido praticamente todos os locais habitáveis. O solo cultivável foi, enfim, desvendado. Obviamente, os povos que originariamente se dividiram não mantinham mais contato, tendo inclusive se diferenciado fisicamente (esse fenômeno ocorreu durante milhares de anos).

A fixação do homem ao solo pode ser atribuída também à relação entre crescimento populacional e a escassez de matéria consumível. A taxa de natalidade definia o futuro das comunidades: permanecer mais tempo explorando uma área, ou ir à procura de outra que atenda a nova demanda. O nascimento de mais um implicava na ampliação da área necessária para satisfazer a quota de alimentação exigida (e de outros produtos exigidos para a vida).

Essa mudança do nômade para o fixo, caçador para o criador, deu-se essencialmente pelo implemento da agricultura. $\mathrm{O}$ aproveitamento direto do solo permitiu a constituição de uma sociedade enraizada, que aprendeu a conviver com técnicas de exploração e de produção eficazes.

A sociedade fixa compreendeu a propriedade no sentido comunitário. A coisa era de uso coletivo, de propriedade comunitária, não sendo possível identificar o que pertencia ao indivíduo determinado.

Nesses povos comunitários, a noção meu e seu existia, porém restrita aos utensîlios de uso pessoal, tais como roupas e ferramentas. O local de cultivo, moradia, pesca e caça era de destinado a todos. A estrutura das sociedades da época permitia a segmentação em funções, atribuindo-se às homens tarefas não destinadas às mulheres. Isso não afastava o caráter comum do solo e das demais coisas úteis. 
O aumento populacional novamente era um problema. De um lado, a limitação espacial, de outro, o avanço das técnicas de produção e cultivo. A opção de migrar novamente existe, porém fica restrita, pois os territórios vizinhos já foram explorados. O método de produção comunitária pode ter chegado ao seu limite. A eficiência dessa forma de cultivo ficaria sujeita ao comprometimento pessoal de cada indivíduo, o que, sabemos, nem sempre é igual. A aptidão para o desempenho das funções atreladas à lida com a terra depende de cada um.

A tensão gerada pela superpopulação fez com que a limitação dos recursos gerasse a diminuição do bem-estar, ou seja, da qualidade de vida. A necessidade de maior produção de alimentos implicou no avanço da tecnologia da produção de alimentos. Além disso, esse limite levou ao desencadeamento de conflitos, que, aliás, ainda hoje podemos encontrar.

Então, uma das justificativas da existência inicial da propriedade privada é a necessidade de aprimoramento da relação da demanda-oferta, que nada mais é do que a impositiva exigência de eficiência. A repartição do solo foi a saída encontrada para racionalizar a fonte de riquezas, de modo a proporcionar maior qualidade de vida. Daí surgiu a produção para a subsistência, e a ainda a negociação do excedente (escambo ou mesmo a venda).

Basicamente, a repartição do solo surgiu de uma necessidade econômica. Exemplo disso é a descrição da tragédia dos comuns, (AGUSTINHO, 2011, p. 51), que assenta a essencialidade da propriedade privada para a melhoria do grau de aproveitamento dos recursos disponíveis.

A utilização de porção de terra comunitariamente importa também na divisão de tarefas para o seu cultivo. Essa relação pode ser satisfatória e gerar ganhos a todos. No entanto, basta que um dos pastores decida incluir na criação coletiva mais uma ovelha e essa relação é alterada. A propriedade coletiva aumenta, e as responsabilidades também. Isso poderia muito bem ser suportado por todos, visto que o trabalho será diluído entre todos. Ocorre que o desequilibrio começa quando os demais pastores decidem incluir mais uma ovelha cada. A disponibilidade de pasto para cada ovelha diminuirá, importando em ineficiência, ou seja, em falta em perda da oportunidade de utilização o máxima, ou ótima, do solo.

A compreensão da utilidade da propriedade privada é tema relevante para a economia, encontrando-se inserida no amplo campo da Análise Econômica do Direito (AED), porquanto o seu objeto diz respeito às alternativas de escolha.

Ivo Teixeira Gico Junior ensina:

Assim, quando se fala em análise econômica não estamos nos referindo a um objeto de estudo específico (e.g. mercado, dinheiro, lucro), mas ao método de investigação aplicado ao problema, o método econômico, cujo objeto pode ser qualquer questão que envolva escolhas humanas (e.g. litigar ou fazer acordo, celebrar ou não um contrato, poluir ou não poluir). (GICO JUNIOR, 2011, p. 19-20). 
Ao poder de decidir entre dois rumos é dado o nome de oportunidade. Cabe ao agente escolher, segundo o que apreendeu pelos seus sentidos e dentro de um mínimo de racionalidade. Toda escolha pressupõe riscos, que pressupõe a análise da fruição, do gozo, como também pode significar o risco de perder menos, ou seja, do que lhe trará menor prejuízo.

Assim, a escolha do regime de exploração dos recursos imobiliários é afeta ao AED, bem como o conjunto de normas jurídicas correlatas. O fracionamento do solo foi a opção encontrada para solucionar o problema da utilização com eficiência. A atribuição de pertencimento exclusivo foi a forma encontrada para solver essa oportunidade.

O tratamento conferido a propriedade privada variou na história. Por muito tempo, sustentou-se que a propriedade era um direito natural dos homens. A condição de pretensa superioridade frente aos demais seres permitia-lhes apropriar-se das coisas. A sustentação desse argumento tem origem filosófica e religiosa, sendo compreendido como um instrumento de manifestação absoluta do homem, sem que outros pudessem sobre ele exercer qualquer forma de poder (exceto as naturais).

Não desmerecemos o papel dogmático e de dominação dessa compreensão. A sociedade mantinha-se com esse desnivelamento justificado de classe. A propriedade privada tinha conotação eminentemente individual, pelo que a função social que hoje nos parece evidente não era conhecida, senão a função pessoal. No Direito romano podemos encontrar essa orientação absolutista da propriedade.

O regime feudal foi uma manifestação desse processo, no sentido de que o proprietário das terras manteria sob seus domínios os que não tinham acesso ao direito que lhes era assegurado. E os que não detinham esse poder, estavam confinados a viver como faziam os pastores do conto acima, com a exceção de que a partilha do produto que obtinham era totalmente desigual.

Já no final do século XVIII a propriedade privada foi alçada à base da sociedade que tomaria o poder. Um dos pontos que levaram à revolução francesa foi a desproporção entre o poder manifesto pela elite nobre e a burguesia. As titulações da classe até então dominante sucumbiria, ao menos parcialmente, ao intento patrimonial individual. O poder que fortaleciase basicamente pela herança sucumbia-se à manifestação da igualdade.

A diferença entre o sistema de propriedade até então vigente é a possibilidade de se alcançar o poder pela propriedade privada, o que significaria a defesa da própria democracia. O Código Francês de 1804 reproduzia o ideário liberal da propriedade privada ao estatuir: "537. Les particuliers ont la libre disposition des biens qui leur appartiennent, sous les modifications 
établies par les lois". A única limitação era a lei (que reafirmava o império da igualdade, porquanto eram promulgadas sob os mesmos fundamentos libertários).

A propriedade foi alçada a direito natural e imprescritível do homem, segundo a Declaração Universal dos Direitos do Homem e do Cidadão de 1789, ponto máximo do movimento libertário francês.

A esse sistema de propriedade justificada pela igualdade e liberdade contrapôs-se o movimento comunista. Apontando que a história da humanidade seria uma luta de classes, (MARX; ENGELS, 2011, p. 23), Karl Mark e Friedrich Engels afastaram os benefícios da propriedade privada. Para eles, a solução para a desigualdade era o fim do domínio particular sobre bens escassos. A socialização seria a ferramenta para que as diferenças geradas pelo capitalismo. Os comunistas justificavam a abolição da propriedade privada na ineficiência do aproveitamento desses bens (produtividade). A preocupação era dúplice: com a injustiça e com a equação econômica desequilibrada.

Há quem refute os argumentos comunistas com a problemática do interesse em produzir mais, vigente no capitalismo. Didaticamente, Ubiratan Jorge Iorio ensina:

\footnotetext{
Por fim, temos que falar da importância da propriedade privada para o desenvolvimento individual: se você fosse um fazendeiro da Sibéria no tempo do comunismo e uma das vacas (que eram de propriedade do governo) estivesse para morrer de frio, dificilmente você deixaria a sua cama às duas horas da manhã para salvá-la, porque a vaca não era sua, era do estado. Mas, se ela fosse sua, primeiro, você cuidaria para que ela não sentis se frio, gastando em equipamentos de calefação e, segundo, mesmo que ela viesse a sentir muito frio, você com certeza deixaria a sua cama para salvá-la, sabe por quê? Simplesmente porque ela lhe pertencia!. (IORIO, 2013, p. 14-15).
}

Entretanto, é inegável o mérito cientifico da obra comunista. Uma das consequências desse pensamento é a ampliação da destinação da propriedade. Não seria vista mais como um poder totalitário do homem, mas era vocacionada a exercer uma função social.

A Constituição de Weimar foi o ápice desse pensamento, firmando um claro rompimento à orientação liberal, que estava em evidente crise. A propriedade passaria a ser exercida em prol de seu titular e do bem comum.

Essa ordenação social democrata fundou o Estado social e replicou nas posteriores constituições de vários países, como o México e o Brasil. Aqui, a função social da propriedade está expressamente prevista no art. $5^{\circ}$, inciso XXIII (direitos e garantias fundamentais), no art. 170, inciso III (princípios da atividade econômica), no art. 182, § $2^{\circ}$ (política urbana), e no art. 
184, caput e parágrafo único, e no art. 186 (ambos da política agrícola e fundiária). O que reforça a preocupação do Estado com a socialização (ou funcionalização) da propriedade privada sob vários aspectos da relação do Poder com a proprietário (e a coisa).

A mudança de tratamento jurídico da propriedade privada impôs verdadeira alteração no conteúdo de tal direito fundamental, o que implica em reformulação do significado efetivo e prático de propriedade. Houve uma mudança de sentido, que espelhou-se nos acontecimentos históricos.

José Afonso da Silva orienta de modo similar:

\begin{abstract}
Mas é certo que o princípio da função social não autoriza a suprimir, por via legislativa, a instituição da propriedade privada. Contudo, parece-nos que pode fundamentar até mesmo a socialização de algum tipo de propriedade, onde precisamente is so se torne necessário à realização do princípio, que se põe acima do interesse individual. Por is so é que se concluique o direito de propriedade (dos meios de produção especialmente) não pode mais ser tido como um direito individual. A inserção do princípio da função social, sem impedir a existência da instituição, modifica sua natureza, pelo que, como já dissemos, deveria ser prevista apenas como instituição do direito econômico. (SILVA, 2005, p. 284).
\end{abstract}

A propriedade privada imobiliária, objeto do presente estudo, é direito fundamental que o Estado deve garantir. Para isso, fez-se necessário a estruturação de um regime ou sistema de publicidade que assegurasse o invariável e seguro exercício desse direito. A funcionalização da propriedade não impede a sua integral proteção, desde o momento em que é constituído até o findar da desconstituição.

A propriedade imobiliária, dado o grau de relevância para o Direito, merece ser protegida. Pelo regime constitucional, a cada direito fundamental corresponde uma garantia, ou uma ferramenta que o assegure.

No história nacional do sistema de proteção imobiliária, o Estado brasileiro optou por, inicialmente, segregar o acervo público do privado. A Lei de Terras de 1850 teve esse condão, ao legitimar a posse rural. Posteriormente, com a Lei hipotecária de 1964, o Brasil visualizou o primeiro sistema registral instituído (registro geral), o que demonstra a orientação que a propriedade privada sempre ostentou: o recurso escasso voltado à produção e circulação de mercadorias, ou seja, um sistema registral essencialmente destinado à proteção do crédito. 
Com a Lei de Registros Públicos, de 1924, o sistema legal de segurança jurídica da propriedade era orientado para a descrição dos títulos de transmissão, guiando-se, assim, pelo direito obrigacional e pelo foco nas pessoas envolvidas.

A Lei de Registros Públicos de 1973 determinou a ruptura do sistema pessoal de publicização das informações imobiliárias. O imóvel passou a ser a base registral. A matrícula foi instituída. A evolução foi evidente, de modo que tornou mais eficiente o procedimento de garantia da propriedade. Não houve, no entanto, efetiva alteração na segurança jurídica da propriedade privada, posto que o sistema pessoal também permitia a sua proteção integral. A alteração foi da forma de disposição e tratamento das informações, não do conteúdo do direito.

No entanto, a despeito de ter sido instituído para a proteção do direito de propriedade, o sistema registral assegura o conjunto de poderes inerentes a ele. $\mathrm{O}$ regime de publicidade imobiliária garante que os desdobramentos da propriedade possam ser fraccionados sem que isso incorra em riscos ao proprietário.

Afrânio de Carvalho leciona:

Os registros púbicos são instituídos para tutela ou proteção dos direitos. A lei não se limita a reconhecer os direitos subjetivos, mas ainda os protege brindando-os com os registros. Esses registros dão ao público a certeza não só sobre as pessoas, naturais ou jurídicas, que são os sujeitos de direitos, com sobre os bens, que são objeto deles, e ainda sobre as relações jurídicas, das quais eles derivam. Graças aos registros, as transmissões ou mudança de titularidade são revestidas de publicidade. (CARVALHO, 1980, p. 385).

Os registros públicos imobiliários são chamados de Registros de Imóveis. As características, as vantagens e desvantagens do sistema serão delineados no próximo capitulo. O que fica por ora é a compreensão de que o Brasil adotou o sistema romano-germânico de proteção à propriedade privada, o que significa dizer que o norte é a segurança jurídica.

O delineamento da forma de pensar o Estado, obviamente, influencia as instituições que dele derivam. Portanto, o sistema de proteção do direito de propriedade desenvolveu-se durante os séculos, acompanhando a estrutura das sociedades.

A forma de constituição do regime de segurança imobiliária encontra diversas facetas, variando conforme a cultura da sociedade, dos seus valores, bem como do grau de liberdade que pregam. 
O Brasil não foi diferente. Edificou o sistema registral de modo a tentar reconhecer o povo brasileiro e as vicissitudes que nos é peculiar. Adaptou-se, ainda, à extensão do seu território, capilarizando-se.

Veremos, então, os méritos do regime adotado, demonstrando o grau de autenticidade dos índices utilizados para desacertá-lo.

\section{SISTEMA DE PROTEÇÃO DA PROPRIEDADE}

O sistema de publicidade registral adotado no Brasil tem foco na segurança jurídica. Esse sistema é chamado de romano-germânico, como acima já foi mencionado. A pauta é evitar conflitos, ou seja, perpetuando a paz social. O registrador de imóveis, portanto, visa a não existência de litígios, ou seja, a pacificação.

O fim dos registros públicos é a de assegurar que a propriedade imobiliária seja exercida em sua plenitude, sem percalços de qualquer ordem. A própria discussão dos efeitos prospectados de determinado registro pode colocar em risco a ordem de manutenção do status de calmaria. O que se pretende demonstrar é exatamente que a estabilidade é o postulado dos registros. A instabilidade é a tormenta que todo o sistema refuta.

Os Estados Unidos, por exemplo, adotaram sistema diverso. Não há um sistema de registro de direitos. Os títulos de transmissão são ordenados, quando muito. A norma aplicada à espécie não é nacional. Os Estados definem a forma do sistema de publicidade.

Sobre o regime americano, Frederico Henrique Viegas de Lima descreve:

\footnotetext{
Nos Estados Unidos não existe um sistema de registro de direitos ou mesmo de títulos único, definido pelo Governo Federal. O denominado recording system é realizado porcada um dos Estados, dentro de seu território, sistematizando-o por condados. Por tal sistema, que não é único, e de acesso livre à população, em realidade o que existe é uma enorme livraria de documentos de inter-relação de documentos que incluem os instrumentos (contratos etc.) que foram utilizados para a formalização da transação imobiliária anterior e que, voluntariamente, foram publicizados pelo interessado, passando a integrar a livraria. Dessa forma, para uma investigação destinada ao conhecimento de uma "cadeia dominial" se torna indispensável a ida do interessado ou "pesquisador" ao public office de cada condado para visitar a livraria, mediante a utilização de um "índice" de catalogação usualmente realizado por pessoas (e não por imóveis) na tentativa de identificar e ler os documentos que se encontraram depositados e que são relacionados coma propriedade que se pretende transacionar. Daí, o interessado, fundado em seus conhecimentos legais e de direito de propriedade, deve decidir e descobrir quem é o verdadeiro proprietário e se existem direitos (encumbrances) que afetem a propriedade, tais como hipotecas, servidões, contratos de leasing, dentre outros. (LIMA, 2014, p. 228).
} 
E continua:

\begin{abstract}
O sistema é frugal (modesto ou simples), conforme apontam Stoebuck e Whitman, semque haja nenhuma responsabilidade do Estado, eis que seus funcionários somente recebem, copiam, indexame devolvem o documento ao seu titular. Sendo tal sistema, para os autores "unfortunately, the recording is seriously deficient with respect of the reliability of information it yields to searchers". Se trata de um sistema custoso em termos de tempo e de dinheiro, quando na grande maioria das vezes a pesquisa deve remontar à propriedade da Coroa Inglesa, fazendo com que os dados de pesquisa remontem somente a 30 ou 40 anos, aumentando a incerteza. Por tais deficiências alguns Estados americanos, concretamente nove Estados (atualmente utilizado no Havaí, no Condado de Cook [Chicago], Henepin [Minneapolis], Ramsey [St. Paul], e algumas áreas de Ohio e Massachusetts), a ilha de Guam na Micronésia e Porto Rico, tenham adotado o sistema torrens de title registration. Contudo o sistema torrens "adaptado" utilizado nesses locais é facultativo, permitindo sua coexistência com o sistema de títulos e mesmo o seguro de títulos. A não adoção do sistema torrens em larga escala se deve a dois fatores: seu alto custo e a dificuldade de estabelecimento de um marco inicial da propriedade imobiliária. Todas essas deficiências fizeram com que outros sistemas, de cunho eminentemente privados - muitas vezes organizados pelas entidades financeiras - proliferassem. Podendo ser destacados: search methods; chain-of-titles; marketable title acts. E, principalmente, os title plants privados e os titles insurances. A diversidade de sistemas nos Estados Unidos e sua pouca confiabilidade foram fatores determinantes para o surgimento da bolha imobiliária em 2008. (LIMA, 2014, p. 228).
\end{abstract}

O autor é preciso na exposição. O sistema americano não proporciona segurança jurídica como acreditam alguns. Ele é disperso e confuso. Assemelha-se com o nosso Registro de Títulos e Documentos, pois a qualificação não é feita para a verificação da compatibilidade dos direitos com o ordenamento jurídico. Lá a análise é perfunctória. Todo o sistema vigente baseia- se na ideia da securitização. Ao adquirir a propriedade de determinado bem imóvel, o adquirente pactua a contratação de seguro, que garante a cobertura dos riscos inerentes ao negócio jurídico. E como é recorrente nas contratações securitárias, o pagamento do prêmio é anual.

A transmissão de propriedade imobiliária nos Estados Unidos é custosa e insegura. Todo sistema é firmado sob premissas do mercado. Não é possível dizer que não há segurança jurídica, até porque existe um grau de verificação de legalidade. Entretanto, a proteção de direitos como conhecemos é incipiente. Pode se dizer, assim, que reduziram a intensidade da segurança jurídica pela promessa de restituição em dinheiro, caso ocorra algum infortúnio.

Poderíamos dizer então que o sistema americano é remediador, e não preventivo. Trabalha com a reparação dos danos. Pressupõe a resolução de eventual controvérsia ou mesmo litígio pelo pagamento do valor previsto no seguro. 
Os contratos de transmissão imobiliária são instrumentalizadas por advogados contratados diretamente pelas partes, dentre profissionais licenciados para tanto. Aqui reside uma outra diferença entre os sistemas: normalmente, atribui-se aos países da commom law a caraterística de que os notários não gozam do atributo do poder de aconselhamento das partes. Já nos países da civil law os notários ostentam essa qualidade, pelo que chamamos de notariado do tipo latino, identificando-os por diversas características, como (i) imparcialidade, (ii) profissionais do direito, (iii) aconselhador, (iv) independência jurídica, (v) remunerado pelas partes, (vi) de livre escolha, (vii) limites de atuação definidos, (viii) responsabilidade pessoal, (ix) dever de conferir autenticidade aos atos e negócios jurídicos, (x) e a obrigação de constituir protocolo.

Importante lembrar que mesmo alguns países de sistema jurídico diverso adotam, paulatinamente, o tipo latino de notariado, como, por exemplo, o Japão e a China. Aqui, colaciono a contribuição de Leonardo Brandelli:

\begin{abstract}
Essa espécie de notários, por sua eficácia e importância,é adotada em mais de setenta países do mundo, como, por exemplo, Espanha, Itália, França, Portugal, Alemanha, Áustria, Albânia, Bélgica, Canadá, Japão, Luxemburgo, Mônaco, México, Argentina e Vaticano, dentre outros.

Interessante fenômeno de valorização do notariado do tipo latino ocorreu recentemente, após a queda do muro de Berlim e dos regimes comunistas, quando, com o brotar do direito libre de propriedade e dos contratos nos países afetados por esse fenômeno, fez-se necessário optar por um sistema notarial. Ante a possibilidade de eleger o sistema anglo-saxão ou o sistema latino, a segunda opção foi a escolhida pela segurança jurídica que traz consigo. (BRANDELLI, 2009, p. 74).
\end{abstract}

Assim, no Brasil a transmissão da propriedade privada depende, em geral, da participação de dois profissionais do direito: o registrador de imóveis (ou oficial de registrado) e o notário (ou tabelião de notas). $\mathrm{O}$ art. 108 do Código Civil excepciona a exigência deste profissional nos negócios jurídicos que envolvam imóveis de valor superior a 30 saláriosmínimos. Há ainda disposições especiais que permitem a utilização de instrumentos particulares para a constituição de direitos (Lei n ${ }^{\circ}$ 9.514/97).

A Constituição Federal de 1988, no art. 236, reconhecendo a importância de se estabelecer um padrão normativo para as atividades voltadas à segurança do transito 
imobiliário, determinou que esses profissionais sejam selecionados em concurso público de provas e títulos, sujeitando-se ao regramento imposto pelo agente regulador (Tribunais de Justiça, por meio de suas Corregedorias-Gerais da Justiça, e o Conselho Nacional de Justiça). O marco constitucional dos serviços notariais e de registro, portanto, é a atribuição de atividade estatal a particular, de acordo com a tendência privatizadora e descentralista que permeio a doutrina de Estado nas últimas décadas do século XX.

Finalmente, a Lei no 8.935/94 impôs a característica essencial dos profissionais das notas e dos registros: a independência jurídica, que permite a liberdade de qualificação e de decisão. A análise do caso sujeito a apreciação desses profissionais é feita em razão do conjunto de preceitos normativos a que estão sujeitos, especialmente a Lei e os atos editados pelos agentes reguladores. Não estarão sujeitos a responsabilidade administrativa, penal ou civil se agirem dentro dos parâmetros delineados pelo art. 28 da citada Lei.

Os atributos e os traços do sistema de proteção imobiliária permitem determinar a amplitude do custo transacional, compondo as ferramentas para o cálculo do grau de facilidade negocial e do custo brasil.

\section{CUSTOS DE TRANSAÇÃO, FACILIDADE NEGOCIAL E O CUSTO BRASIL}

Não se trata apenas do valor pecuniário dispendido com o custeio dos atos formais necessários à transmissão da propriedade. Custo, aqui, significa a ponderação entre os benefícios e os atrasos que o sistema pode acarretar. Portanto, indica o relação de prejuízo- benefício.

Em termos de aquisição de direitos sobre bens imóveis, o custo diz respeito a duas perspectivas: (i) na amplitude individual, diz respeito a sujeitar-se ao regime legal da escrituração pública ou manter-se dentro da legalidade, porém sem os atributos inerentes ao sistema de garantias registrais-notariais; (ii) na visão global, norteia a compreensão do sistema adotado com as alternativas preteridas.

Neste ponto, chama-se de trade-off a primeira alternativa viável que não foi escolhida. O custo é a chance de ter optado por outra via útil. Bittencourt traduz esse conceito:

Toda escolha pressupõe umcusto, umtrade-off, que é exatamente a segunda alocação factível mais interessante para o recurso, mas que foi preterida. A esse custo chamamos de custo de oportunidade.(BITTENCOURT, 2011, p. 22). 
À primeira concepção de custo, afirma-se que a opção por adentrar ao regime imposto pela legislação registral traz inúmeros benefícios. O Código Civil impõe que a aquisição de direitos reais imobiliários ocorre com o registro do título no Cartório de Registro competente (art. 1.227). Não há, assim, a constituição de direitos reais fora do sistema registral, com exceção das espécies de aquisição originária. E mesmo nessas hipóteses, o registro é indispensável para fins de disponibilidade e oponibilidade erga omnes.

O sistema, assim, não dispensa a participação dos dois profissionais (notário e registrador). Cada um detém feixe de atribuições para a perfectibilização dos atos e negócios jurídicos, permitindo a produção saudável de efeitos.

Salienta-se que o registro de direitos é obrigatório, conforme determina o art. 169 da Lei $\mathrm{n}^{\mathrm{o}}$ 6.015/73 (LRP). Essa imposição determina que os atos elencados no art. 167 da LRP não podem deixar de ser inscritos no fólio real. Qual a sanção para o descumprimento dessa vinculação? A não produção dos efeitos garantidos pela legislação material civil, especialmente a não afetação de terceiros a respeitar os direitos contratados.

Consequentemente, o risco é o que caracteriza o negócio não sujeito ao manto do sistema de proteção. E creio que é justamente o risco que todos pretendemos evitar. A aquisição imobiliária é, muitas vezes, tida como o momento de completude patrimonial do homem. A sujeição a riscos é a opção comum dos que desejam obter vantagens proporcionais. Não é disso que tratamos neste trabalho. Normalmente, os adquirentes pretendem livrar-se do que pode trazer instabilidade.

A publicidade proporcionada pela publicidade registral tem função econômica. As propriedades que gozem de vinculação dominial segura ostentam valores de avaliação maiores. A regularidade registral pode assegurar descompassada liquidez, frente aos imóveis em situação de irregularidade.

Discorrendo sobre artigo de Raquel Sztajn, Decio Zylbersztajn, e Bernardo Mueller, Marcelo Salaroli de Oliveira afirma: 


\begin{abstract}
Amazônia brasileira. Dentre as conclusões, a pesquisa constatou que quanto maior a proximidade da terra com os mercados, maior era o seu valor, comprovando que a possibilidade de transferência afeta positivamente o valor do bem. Concluiu também que quanto mais seguros eram os títulos dos proprietários, maiores investimentos realizam na terra, gerando melhor aproveitamento econômico. (SZTAJN; ZYLBERSZTAJN; 2010, p. 34).
\end{abstract}

A clandestinidade gera a desvalorização da pretensa (pois ainda não constituída) propriedade. Só não haveria esse desequilibrio se todos deixassem de utilizar do sistema legal de transmissão imobiliária, o que é extremamente improvável.

A continuidade da fuga ao regime de publicidade acarretará uma cadeia de insegurança, que importará a elevação nos custos de informação. Aqui chegamos em um dos pontos que separam, quanto ao custo transacional, os sistemas registrais romano-germânicos e anglo-saxão. A onerosidade da informação imposta a todos os que pretendem fazer uso da máquina registral eleva o padrão do risco. A dificuldade na obtenção de conhecimento sobre os acontecimentos juridicamente relevantes impõe certo nível de ameaça à constituição segura de direitos.

Outros dois fatores importantes são a inoponibilidade de fatos fora do registro, que decorre do princípio da boa-fé, e a presunção de veracidade dos atos praticados, imposição da fé pública.

No Brasil, apenas com o advento da Lei $\mathrm{n}^{\mathrm{o}}$ 13.097/2013 o sistema registral passou a conter a primeira característica. O art. 54 fixou o princípio segundo o qual os atos e fatos narrados no fólio registral são oponíveis a todos, sem distinção. Tornou-se efetiva a relação entre a publicidade registral e a presunção de boa-fé. Fatos não contidos na matrícula não podem ser opostos ao adquirente de boa-fé.

A mencionada lei permite concluir que o custo de registro no Brasil foi consideravelmente reduzido. Não é possível quantificar, ainda, o grau de diminuição. No entanto, evidentemente, concentrou-se (por isso alguns chama de princípio da concentração) na matrícula as informações relevantes ao imóvel, mesmo as que não o afetem diretamente.

Quanto à segunda perspectiva, a comparação do sistema de proteção imobiliária brasileira com a estrangeira permite obter certas afirmações (que já foram delineadas, em parte, no capítulo anterior), e que dizem respeito (i) ao custo de informação, (ii) uniformidade de procedimentos; (iii) privatização e descentralização das unidades; (iv) independência jurídica.

O sistema adotado nos Estados Unidos é exemplo de onerosidade. Comparativamente com o método brasileiro, conhecer o status jurídico de determinado imóvel naquele país é tarefa mais dificultoso. Aqui, a matrícula contém todas as informações significativas sobre a condição 
jurídica do imóvel. O que não está descrito no fólio real não pode ser oposto. Qual é o custo de obter essa informação? Com toda certeza, menor do que o determinado pelo sistema americano. Lembrando que o tempo e o valor pecuniário para obter fisicamente a informação não integram o objeto deste estudo. Apesar disso, provando-se que o nosso sistema for monetariamente e temporalmente mais dispendiosos, isso não tem o condão de afastar os benefícios do baixíssimo custo de informação proporcionado.

No que diz respeito à comparação dos custos de transação dos países que adotam o sistema de registro de direitos e o de títulos, Méndez González, citado por Marcelo Salaroli de Oliveira, afirma:

\begin{abstract}
Méndez González nos traz a comparação internacional dos custos de transferência de propriedade de bens imóveis, com dados dos Estados Unidos da América e França, países que adotam o sistema de registro de documentos, em comparação com dados de Alemanha, Espanha, Inglaterra e País de Gales. Nestes, os custos de transação são menores do que naqueles. (MÉNDEZ GONZÁLEZ, 2010, p. 34).
\end{abstract}

A previsão dos riscos é essencial para que a aquisição de direitos ocorra de modo igualitário entre os agentes envolvidos na negociação. Nas atividades empresariais essa prefixação é relevante. Quanto à estabilidade e à segurança no desempenho das obrigações empresariais, Luis Roberto Ahrens determina que

A pretensão, portanto, de promover o continuado desenvolvimento econômico sustentável deve impulsionar a redução do ris co jurídico como aumento da segurança institucional e da certeza no cumprimento das obrigações empresariais avençadas de maneira a possibilitar economia nos custos de transação com efeitos na precificação benéficos à coletividade. (AHRENS; KNOERR, 2012, p. 10).

O que dizer então dos relatórios internacionais que apontam o Brasil como país atrasado em termos de facilidade negocial? A compreensão da metodologia é importante.

No relatório Doing Business 2016, (BANDO MUNDIAL, 2016). do Banco Mundial, indica que o Brasil ocupa a posição $116^{\mathrm{a}}$ quanto à facilidade de fazer negócios, dentre os 189 países avaliados. Esse relatório divide os marcos legais das nações em quesitos, que são: $a$ ) starting a business; b) dealing with construction permits; c) getting electricity; d) registering property; e) getting credit;f) protecting minority investors; g) protecting minority investor; $h$ ) paying taxes; i) enforcing contracts; j) trading across borders; e k) resolving insolvency. 
O quesito registering property é o que nos interessa. O Brasil ocupa a posição $130^{\mathrm{a}}$ neste ponto, o que demonstra certo grau de prejuízo frente à média dos demais traços avaliados. Ele se subdivide em outros quatro quesitos: d.1) procedures (number); d.2) time (days); d.3) cost (\% of property value); d.4) quality of land administration index.

Da análise desses subquesitos podemos concluir que o número de procedimentos é 13,6; o tempo perdido foi o de 31,7 dias; o custo em relação ao valor do imóvel é de 3,1\%; e o índice de qualidade da administração fundiária, numa escala de 0-30, foi de 13,6.

Aparentemente, quando ao custo monetário da transação $(3,1 \%$ do valor de mercado do bem), podemos afirmar que isso leva em consideração o valor global, ou seja, inclui o pagamento do imposto de transmissão ao ente tributário competente. Isso é auferido na página 170 do relatório, que expõe o aumento do custo mediante a imposição tributária, quando afirma que o "Brazil made transferring property in São Paulo more expensive by increasing the property transfer tax".

Quanto ao número de procedimentos, o Banco Mundial determina a participação de agentes externos no processo de transferência imobiliária, visto que "procedure is defined as any interaction of the company founders with external parties (for example, government agencies, lawyers, auditors or notaries)". Neste ponto, não foi preciso quem participa deste processo no Brasil, apenas fazendo-se menção ao número de procedimentos, qual seja, 13,6. Aqui, podemos afirmar que as exigências do sistema de proteção imobiliário se resumem a dois: tabelionatos de notas e os ofícios de registro. As demais partes no processo não dizem respeito a eles, podendo incluir a prefeitura, órgãos certificadores, governo federal, estadual, órgãos de administração fazendária, órgãos da justiça, dentre outros.

Podemos, então, afirmar que o custo transacional poderia ser reduzido se houvesse a facilidade de obtenção dessas informações, mediante a uniformização de plataformas eletrônicas para o satisfação das exigências legais. $\mathrm{O}$ número de procedimentos não diminuiria, mas o tornaria menos oneroso.

No subquesito tempo, a legislação registral impõe o prazo máximo de 30 para o registro de direitos (art. 188 da LRP). O relatório indicou que o tempo dispendido é de 31.7. Abstendose do fato de que nesse prazo incluem procedimentos não registrais, como obtenção de certidões e outros atos necessários, entendemos que o limite temporal indicado na lei merece ser revisto. Não há como se conceber atualmente que as pessoas aguardem esse prazo para terem acesso ao registro. Há que se estabelecer prazo bem menor para a recepção positiva desses direitos. 
Quanto ao último subquesito, qual seja, o índice de qualidade da administração fundiária, é possível colocar duas coisas: a) o nosso processo de ocupação do solo surgiu deficitário (sesmarias, fólio pessoal, legitimação da posse por declaração, etc); b) o território brasileiro impõe certas dificuldades no seu controle. Apesar disso, o relatório dispõe sobre os municípios de São Paulo e Rio de Janeiro, o que, teoricamente, afasta a segunda colocação.

Ainda, analisando o relatório podemos concluir que o custo monetário para a transferência imobiliária não diz respeito diretamente ao grau de facilidade negocial. Isso porque se compararmos uma economia como a dos Estados Unidos, que ocupa a $7^{a}$ posição no ranking de facilidade negocial, o custo pecuniário é de $2,4 \%$. Já a Federação Russa, que ocupa a $51^{\text {a }}$ posição, o custo é de $0,2 \%$. No Qatar, por exemplo, o custo é de $0,3 \%$, e ocupa a $68^{\mathrm{a}}$ posição no ranking de facilidade de fazer negócios.

Isso implica concluir que a relação entre custo pecuniário do sistema de transmissão dos direitos de propriedade não é diretamente relacionado ao seu grau de facilidade negocial ou do atraso em permitir o estabelecimento de novos empreendimentos. São fatores distintos. O que não afasta a possibilidade de chegarmos à conclusão de que devemos refletir sobre o grau de eficiência que queremos, especialmente quanto a forma de prestação do serviço público ao usuário, visto que em termos de segurança jurídica já estamos bem avançados.

\section{CONCLUSÃO}

O sistema registral e notarial brasileiro proporcionam segurança jurídica ao trafego imobiliário. A nossa tradição germânico-romana assenta as premissas de um regime de publicidade eficiente, que garante a eficácia, a autenticidade, e a presunção de veracidade dos atos praticados.

Comparativamente, o regime adotado no Brasil é mais seguro do que o adotado em países do sistema anglo-saxão, como os Estados Unidos. A obtenção das informações necessárias ao deslinde negocial ocorre de forma menos custosa.

Os indicadores internacionais que apontam o Brasil como um país de retrocesso negocial, ou seja, que edifica um ambiente desfavorável aos negócios não prospera em termos de segurança jurídica.

O custo transacional é menor no Brasil, visto que os riscos do negócio são praticamente afastados, considerando a presunção de boa-fé dos adquirentes diligentes, ou seja, dos que 
buscam as informações registrais unificadas no fólio real. A Lei $n^{\circ}$ 13.097/2015 determinou o fortalecimento do sistema de proteção aos direitos reais imobiliários, posto que assegura a prevalência das informações registrais, afastando a oponibilidade de fatos não informados no registro.

O que pode passar uma imagem de atraso aos serviços registrais são, basicamente, fatores externos, como o formalismo na obtenção de licenças, certidões, alvarás, que denotam a característica típica do funcionalismo público, e que se contrapõe ao regime privado de execução das notas e dos registros.

Afirma-se, então, que não há direta relação entre o grau de facilidade negocial dos países e o custo transacional. Em verdade, é imensurável o custo da segurança jurídica. O que é possível comprovar é que o custo pecuniário para o registro dos direitos reais não está proporcionalmente ligado ao indicador de facilidade para fazer negócios do Banco Mundial.

Finalmente, o estudo permite asseverar que podemos avançar. A segurança jurídica proporcionada pelo sistema adotado demanda a constante busca por novas soluções. O desafio é superar os entraves e as amarras. O subquesito tempo, por exemplo, deve ser melhorado, no sentido da admissão de práticas céleres, que em nada afetarão a independência jurídica e a qualificação registral.

\section{REFERÊNCIAS}

AHRENS, Luis Roberto; KNOERR, Viviane Coêlho de Séllos (Orient.). Segurança institucional e desenvolvimento. Curitiba, 2012. 118 f. Dissertação (Mestrado em Direito Empresarial e Cidadania) - Centro Universitario Curitiba, Curitiba, 2012.

BANCO MUNDIAL. Relatório Doing Business 2015. Disponível em <https://openknowledge.worldbank.org/bitstream/handle/10986/20483/DB15-FullReport.pdf?sequence=1\&isAllowed=y>. Acesso em 16/01/2016.

BANDO MUNDIAL. Relatório Doing Business 2016. Disponível em: $<$ http://portugues.doingbusiness.org/ /media/GIAWB/Doing\%20Busines s/Documents/Annua 1-Reports/English/DB16-Full-Report.pdf>. Acesso em 17/01/2016.

BRANDELLI, Leonardo. Teoria geral do direito notarial. $3^{\text {a }}$ ed. São Paulo: Saraiva, 2009. CARVALHO, Afrânio de. Instituições de direito privado. $3^{\text {a }}$ ed. Rio de Janeiro: Forense, 1980. 
CONSTANTINO, Rodrigo. Despachante e burocracia: os brasileiros espertos e os americanos bobalhões. Disponível em <http://rodrigoconstantino.com/artigos/despachante-e-burocraciaos-brasileiros-espertos-e-os-americanos-bobalhoes/>. Acesso em 16/01/2016.

ESTUDANTES PELA LIBERDADE. Ranking de liberdade econômica. Disponível em <http://www.liberdadeeconomica.com.br>. Acesso em 16/01/2016.

IORIO, Ubiratan Jorge. Dez lições fundamentais de economia austríaca. São Paulo: Instituto Ludwig von Mises Brasil, 2013.

LIMA, Frederico Henrique Viegas de. O registro de direitos diante da crise imobiliária global. In: Revista de Direito Imobiliário. São Paulo, ano 37, vol. 77, jul/dez. 2014.

MARX, Karl; ENGELS, Friedrich. Manifesto do partido comunista. Tradução de Sueli Tomazini Barros Cassal. São Paulo: L\&PM Editores, 2011.

OLIVEIRA, Marcelo Salaroli de. Publicidade registral imobiliária. São Paulo: Saraiva, 2010. RIBEIRO, Marcia Carla Pereira; KLEIN, Vinícius (Coord). O que é análise econômica do direito: uma introdução. Belo Horizonte: Fórum, 2011.

SILVA, José Afonso da. Curso de direito constitucional positivo. $24^{\mathrm{a}}$ ed. rev. atual. São Paulo: Malheiros, 2005. 